\title{
Analgesia following startle-eliciting stimuli
}

\author{
JACQUELYN CRANNEY \\ University of New South Wales, Kensington, New South Wales, Australia
}

\begin{abstract}
This study investigated the possibility that startle-eliciting stimuli could produce analgesia, as measured by paw-lick latencies on a hot-plate analgesia test. Sixteen rats were tested in a $2 \times 2$ design: drug (saline, naloxone) $\times$ treatment (startle, no startle). First, rats were administered the naloxone $(4 \mathrm{mg} / \mathrm{ml} / \mathrm{kg}$ ) or the saline. One minute following injection, the startle groups were presented with noise bursts at 60 -sec intervals, and the no-startle groups received $10 \mathrm{~min}$ of exposure to the chamber, with no noise bursts. The hot-plate test was then administered. Two hours later, the rats were returned to the startle chamber for $60 \mathrm{sec}$. The paw-lick latencies of the startle groups were significantly longer than those of the no-startle groups, suggesting that startle produces stress-induced analgesia. The naloxone-startle group had a shorter latency than the saline-startle group, suggesting that the stress-induced analgesia is partly opiate-based. There were no significant differences between the naloxone-startle and saline-startle rats in startle amplitude or freezing. When returned to the startle chamber $2 \mathrm{~h}$ later, however, the naloxone-startle rats froze more than did the saline-startle rats.
\end{abstract}

Exposure to a variety of different stressors results in decreased responsiveness to pain sensitivity for a period that usually outlasts the duration of the stimulus (Hayes, Bennett, Newlon, \& Mayer, 1978). Stress-induced analgesia was once thought to be mediated by endogenous opioid peptides (Akil, Madden, Patrick, \& Barchas, 1976); however, more recent evidence led Watkins and Mayer (1982) to conclude that there were many forms of stressinduced analgesia, with clear evidence for opioid/hormonal, opioid/nonhormonal, and nonopioid types.

Many different kinds of stimuli seem to provoke an analgesia mediated by endogenous opioids; most of these stimuli are either painful or associated with pain. This experiment examines the possibility that a startle-eliciting stimulus, usually thought to be nonpainful (e.g., Warren \& Ison, 1982), might also provoke an analgesia mediated by endogenous opioids. This might be expected because previous studies (Borszcz, Cranney, \& Leaton, 1985; Cranney, 1987) suggest that the startle stimulus is capable of supporting conditioned freezing in the experimental context. This implies that the startle stimulus is aversive and may elicit a nociceptive response, and thus produce an analgesia somewhat similar to that induced by low levels of shock.

The freezing response is one of the rat's species-specific defense reactions (Bolles, 1970), and it can be conditioned to the apparatus stimuli that have been associated with an aversive stimulus, such as shock (e.g., Fanselow, 1980). Fanselow (1981, 1984; Fanselow \& Bolles, 1979) reported that naloxone, an opiate antagonist, enhanced the reaction to the aversive stimulus; he argued that naloxone enhanced the perceived intensity of the shock by an-

Address reprint requests to: J. Cranney, School of Psychology, University of New South Wales, P.O. Box 1, Kensington, NSW 2033, Australia. tagonizing endogenous opioid analgesic systems. He also argued that these effects were specific to nociceptive stimuli and, in particular, that these effects did not occur with an acoustic startle stimulus. Borszcz et al. (1985), however, reported that the freezing that normally develops during the first few days of startle habituation training was affected by manipulations that affected conditioning, such as latent inhibition and extinction. They concluded that the increased startle responsiveness and freezing behavior that they observed resulted from the formation of an association between the initially aversive startle stimulus and the contextual stimuli of the startle apparatus. In terms of opioid manipulations, Cranney (1987) reported that a higher startle stimulus intensity and naloxone pretreatment increased context-conditioned freezing. It thus appears that the acoustic startle stimulus may have nociceptive or other aversive properties that can support a conditioned response, particularly freezing to contextual stimuli, and that the underlying mechanisms may be opioid in nature. If the startle reflex does somehow engage the endogenous opioid system, then it is possible that it also elicits an opioid-based stress-induced analgesia.

The current experiment tested the possibility that the startle stimulus could produce stress-induced analgesia, as indexed by paw-lick latencies in rats. In addition, the opiate antagonist, naloxone, was administered to half of the animals. If endogenous opiates were involved in mediating startle-induced analgesia, then there should be reduced analgesia in the naloxone animals. Startle and freezing responses were also monitored; on the basis of previous work, it was expected that there would be no significant differences in startle and freezing responses between the groups in Session 1 (Borszcz et al., 1985; Cranney, 1987), but that the naloxone-treated group would show a higher level of context-conditioned freezing in Session 2. 


\section{METHOD}

\section{Subjects}

The subjects were 16 experimentally naive male albino Wistar rats obtained from the University of New South Wales Animal Breeding and Holding Unit and weighing between 370 and $475 \mathrm{~g}$. The rats were housed in large, white plastic boxes $(65 \times 40 \times 22 \mathrm{~cm})$ with 8 animals per box. Water and food were available ad lib. The rats were handled at least $20 \mathrm{sec}$ per day for 4 days before the experiment began. They were handled and tested during the middle of the light portion of a 12:12-h light:dark cycle.

\section{Apparatus}

The apparatus was similar to that described by Leitner and Rosenberger (1983). Briefly, it consisted of a $20 \times 12 \times 12 \mathrm{~cm}$ startle chamber enclosed in a dimly illuminated, sound-attenuated box with an observation window in the front wall. Vertical displacement of the chamber moved a piece of piezoelectric film material attached to a rigid superstructure; this movement produced a voltage in that piezo film that was fed to a storage oscilloscope. The peak positive voltage within a $100-\mathrm{msec}$ window following the onset of the startle stimulus was recorded. Before each rat was placed in the experimental apparatus, the chamber was cleaned with a solution of acetic acid and tap water.

The startle-eliciting stimulus was a 50 -msec burst of white noise with a 0-msec rise/fall time, and with a peak intensity of $110 \mathrm{~dB}$ SPL (re. $20 \mu \mathrm{Pa}$ ). It was delivered through a Tandy Piezo Horn (Type 40-1379), attached at an angle to the frame of the startle apparatus. Continuous white noise ( $70 \mathrm{~dB}$ SPL re. $20 \mu \mathrm{Pa}$ ) masked extraneous auditory stimuli. All test stimuli were superimposed on this background of white noise. Stimulus and background intensities were measured with a Brüel and Kjaer sound-level meter (Type 2235), with a microphone placed in a standard, central position within the chamber.

The hot plate consisted of a clear Perspex cylinder (height $37 \mathrm{~cm}$, radius $10 \mathrm{~cm}$ ) with a copper plate fixed inside it, $10 \mathrm{~cm}$ from its base. The cylinder was positioned in a glass tank $(24 \times 16 \times 38 \mathrm{~cm})$ to which $10 \mathrm{~cm}$ of water had been added. A heating instrument allowed the temperature of the water (and thus the copper plate) to be maintained at $54^{\circ} \mathrm{C}$.

\section{Procedure}

The animals were first matched for weight, and then randomly assigned to one of four cells formed by a $2 \times 2$ factorial design: drug (saline, naloxone) $\times$ treatment (startle, no startle). The rats were administered either saline or naloxone $(4 \mathrm{mg} / \mathrm{ml} / \mathrm{kg}$ ) and placed in the startle apparatus. After $60 \mathrm{sec}$, half of the animals in each drug group were presented with 10 startle-eliciting stimuli at 60 -sec intervals. The other half of the animals were left in the chamber for $10 \mathrm{~min}$; no startle-eliciting stimuli were presented. Immediately following this time in the chamber, all rats were given the hot-plate test. This consisted of placing the rats in the cylinder and measuring the latency to the first paw lick.

During the time that the rat was in the chamber, its behavior was observed according to a time-sampling procedure: Every $2 \mathrm{sec}$, the rat's behavior was scored as either freezing or activity. Freezing was defined as the absence of all visible movement of the body and vibrissae except for movement necessitated by respiration (Fanselow, 1984). The observer was ignorant of the drug administered to the subject. The percentage of samples scored as freezing during the 10-sec period prior to each startle-eliciting stimulus (or nonstimulus, in the no-startle groups) was calculated. Two hours following the beginning of the first session, each rat was placed in the chamber again, and observed for $60 \mathrm{sec}$.

\section{RESULTS}

Table 1 presents the mean paw-lick latencies for each of the groups. Planned $t$ tests indicated that the paw-lick latencies of the startle groups were significantly greater than those of the no-startle groups $[t(14)=2.64$, $p<.05]$. This finding suggests that startle does produce analgesia. The naloxone-startle group had a shorter latency than the saline-startle group $[t(6)=2.73, p<.05]$. This finding suggests that the analgesia is at least in part opiate-based.

For Session 1 data, a two-way analysis of variance of the first and last startle responses of the two startle groups revealed no significant main or interaction effects (see Table 1). The mean percentage freezing over the 10 -sec periods prior to the 10 startle stimuli was also calculated. Across the 10 trials in Session 1, the no-startle groups did not freeze at all, and there was no difference between the saline-startle and naloxone-startle group freezing levels. During the $60 \mathrm{sec}$ prior to the first startle stimulus in Session 2, the naloxone-startle group showed more freezing than did the saline-startle group $[t(6)=1.93$, $p=.05$; see Table 1].

\section{DISCUSSION}

These findings support the notion that the presentation of - repeated, moderately high-intensity startle-eliciting stimuli can elicit analgesia, and this analgesia may be opiate-based, as indicated by the attenuation of analgesia by naloxone administration. On the basis of the freezing data, it could be argued that the startle stimulus had

Table 1

Startle Amplitudes, Percent Freezing, and Paw-Lick Latencies (in Seconds) for Each Group

\begin{tabular}{|c|c|c|c|c|c|c|c|c|c|c|}
\hline \multirow{3}{*}{$\begin{array}{c}\text { Experimental } \\
\text { Group }\end{array}$} & \multicolumn{4}{|c|}{ Startle Trials } & \multicolumn{4}{|c|}{ Freezing Sessions } & \multirow{2}{*}{\multicolumn{2}{|c|}{$\begin{array}{c}\text { Paw-Lick } \\
\text { Latency }\end{array}$}} \\
\hline & \multicolumn{2}{|c|}{1} & \multicolumn{2}{|c|}{10} & \multicolumn{2}{|c|}{1} & \multicolumn{2}{|c|}{2} & & \\
\hline & $M$ & $\overline{S D}$ & $M$ & $S D$ & $M$ & $S D$ & $M$ & $S D$ & $M$ & $S D$ \\
\hline Sal-Startle & 1.7 & 0.4 & 2.6 & 2.3 & 73.0 & 6.7 & 47.5 & 20.7 & 32.3 & 11.2 \\
\hline Nal-Startle & 2.8 & 0.9 & 2.1 & 0.5 & 78.0 & 8.3 & 75.0 & 13.4 & 13.4 & 4.1 \\
\hline Sal-No-Startle & & & & & 0.0 & 0.0 & 4.2 & 7.2 & 8.5 & 3.6 \\
\hline Nal-No-Startle & & & & & 0.0 & 0.0 & 0.0 & 0.0 & 10.9 & 3.5 \\
\hline
\end{tabular}

Note-Sal = saline; $\mathrm{Nal}=$ naloxone. Freezing for Session 1 is the mean of the $10-\mathrm{sec}$ samples prior to each startle stimulus. Freezing for Session 2 is the mean of the 60 -sec observation period $2 \mathrm{~h}$ after Session 1. 
nociceptive properties that contributed to the analgesia, although it should be noted that the intensity used (120 dB) is well below the level at which tissue damage occurs. It may not be necessary, however, to invoke a nociceptive mechanism, because, although shock is commonly employed experimentally to produce analgesia, other stimuli which would not activate nociceptors, such as restraint (e.g., Fanselow \& Sigmundi, 1986), also produce analgesia. It could be argued that stimuli that are not necessarily painful, but that may be associated with situations of adaptive relevance (e.g., sudden loud noises may signal the approach of a predator) will evoke an opioidbased analgesia and defensive behavior, such as freezing.

The finding of a startle-induced analgesia has implications for the use of the startle stimulus to assess other phenomena. In particular, investigators who use the startle stimulus to assess different forms of analgesia (e.g., Leitner, 1985; Warren \& Ison, 1982) should be aware that the startle stimulus itself may produce stress-induced analgesia and concomitant biochemical changes.

The finding that the startle groups showed freezing to the experimental context $2 \mathrm{~h}$ after the initial session suggests the development of context-conditioned freezing, and corroborates previous reports of this phenomenon (Borszcz et al., 1985; Cranney, 1987). That there was more context-conditioned freezing in the naloxone-startle group corroborates a similar finding by Cranney (1987), and suggests an opiate basis to context conditioning. It should be noted that, in Session 1, the average freezing during the 10 prestartle periods was similar for the two groups. This reflects the similar development of freezing in the two groups: both started the session with no freezing, but after three to four startle stimulus presentations, they started to freeze, and by the end of the session, most animals were freezing during the whole of the prestartle sample. In contrast, during the 60 -sec observation period of Session 2, there was a difference in the freezing levels of the two groups, with the naloxone-startle group freezing more, at about the same average level for Session 1. These data suggest that naloxone does not increase the within-session "poststartle" freezing response, which contrasts with Fanselow's (1981; Fanselow \& Bolles, 1979) report that naloxone enhances the postshock freezing response. Rather, in this study, naloxone enhanced the longer term context-conditioned freezing in Session 2. This finding suggests that naloxone has a specific enhancing effect on the context-startle association process.

The results of this experiment suggest that startle can elicit analgesia, and that this analgesia is opiate-based. In addition, the previously reported finding of naloxone- enhanced context-conditioned freezing with startle stimuli was replicated. Future work could investigate the extent to which context conditioning and stress-induced analgesia interact and are mediated by opioid mechanisms; in particular, it may be that the startle-induced analgesia is conditionable to contextual stimuli.

\section{REFERENCES}

Akil, H., Madden, J., Patrick, R. L., \& Barchas, J. D. (1976). Stress-induced increase in endogenous opiate peptides: Concurrent analgesia and its partial reversal by naloxone. In H. W. Kosterlitz (Ed.), Opiates and endogenous opioid peptides (pp. 63-70). Amsterdam: North-Holland.

Bolles, R. C. (1970). Species-specific defensive reactions and avoidance learning. Psychological Review, 71, 32-48.

Borszcz, G. S., Cranney, J., \& Leaton, R. N. (1985). Effects of exposure to the startle apparatus on long-term decrements of the acoustic startle reflex: A long-term sensitization hypothesis. Proceedings of the Eastern Psychological Association, 57, 61. (Abstract)

CranNEY, J. (1987). Startle responding and context conditioning: Naloxone pretreatment and stimulus intensity. Pavlovian Journal of Biological Science, 22, 47-51.

FANSELOW, M. S. (1980). Conditional and unconditional components of postshock freezing. Pavlovian Journal of Biological Science, 15, 177-182.

FANSElow, M. S. (1981). Naloxone and Pavlovian fear conditioning. Learning \& Motivation, 12, 398-419.

FANSELOW, M. S. (1984). Opiate modulation of the active and inactive components of the postshock reaction: Parallels between naloxone pretreatment and shock intensity. Behavioral Neuroscience, 98, 269-277.

FANSELOW, M. S., \& BolLes, R. C. (1979). Naloxone and shock-elicited freezing in the rat. Journal of Comparative \& Physiological Psychology, 94, 736-744.

Fanselow, M. S., \& Sigmundi, R. A. (1986). Species-specific danger signals, endogenous opioid analgesia, and defensive behavior. Journal of Experimental Psychology: Animal Behavior Processes, 12, 301-309.

Hayes, R. L., Bennett, G. J., Newlon, P. G., \& Mayer, D. J. (1978). Behavioral and physiologial studies of non-narcotic analgesia in the rat elicited by certain environmental stimuli. Brain Research, 155, 69-90.

LEITNER, D. S. (1985). Alterations in other sensory modalities accompanying stress analgesia as measured by startle reflex modification. Annals of the New York Academy of Sciences, 467, 82-92.

LeitNer, D. S., \& Rosenberger, M. C. (1983). A simple and inexpensive startle transducer with high output. Behavior Research Methods \& Instrumentation, 15, 508-510.

WARREN, P. H., \& IsON, J. R. (1982). Selective action of morphine on reflex expression to nociceptive stimulation in the rat: A contribution to the assessment of analgesia. Pharmacology, Biochemistry \& Behavior, 16, 869-874.

WATKINS, L. R., \& MAYER, D. J. (1982). Organization of endogenous opiate and nonopiate pain control systems. Science, 216, 1185-1192.

(Manuscript received July 10, 1987; revison accepted for publication January 4,1988 .) 